\title{
Recurrent Transient Monocular Blindness with Ophthalmic Artery Stenosis
}

\author{
Man Seok Park Joon Tae Kim Kee Ra Lee Seung Han Lee Seong Min Choi \\ Byeong Chae Kim Myeong Kyu Kim Ki Hyun Cho \\ Department of Neurology, Chonnam National University Medical School, Gwang Ju, South Korea
}

\begin{abstract}
Dear Sir,
Transient monocular blindness (TMB) or amaurosis fugax (AF) is defined as a monocular, transient visual loss lasting a few minutes, which is caused by an abrupt temporary reduction in blood flow to one eye. From increased blood viscosity to vasospasm or multiple occlusions of extracranial arteries, various mechanisms are involved in causing TMB. One of the most clearly demonstrated mechanisms is atherothrombotic embolism from the carotid artery to the ophthalmic artery. However, TMB caused by isolated ipsilateral ophthalmic artery stenosis is very rare. We experienced a patient with recurrent TMB associated with isolated proximal ophthalmic artery stenosis.
\end{abstract}

\section{Case Report}

A 64-year-old man presented with repeated episodes of transient right-sided monocular blindness during a 4-week period. His symptom began spontaneously with multiple faint speckles that encompassed his entire field of vision. Symptoms appeared suddenly and improved gradually after several minutes or a few hours. TMB attacks tended to occur when he got out of bed early in the morning. He suffered from hypertension for 10 years, but

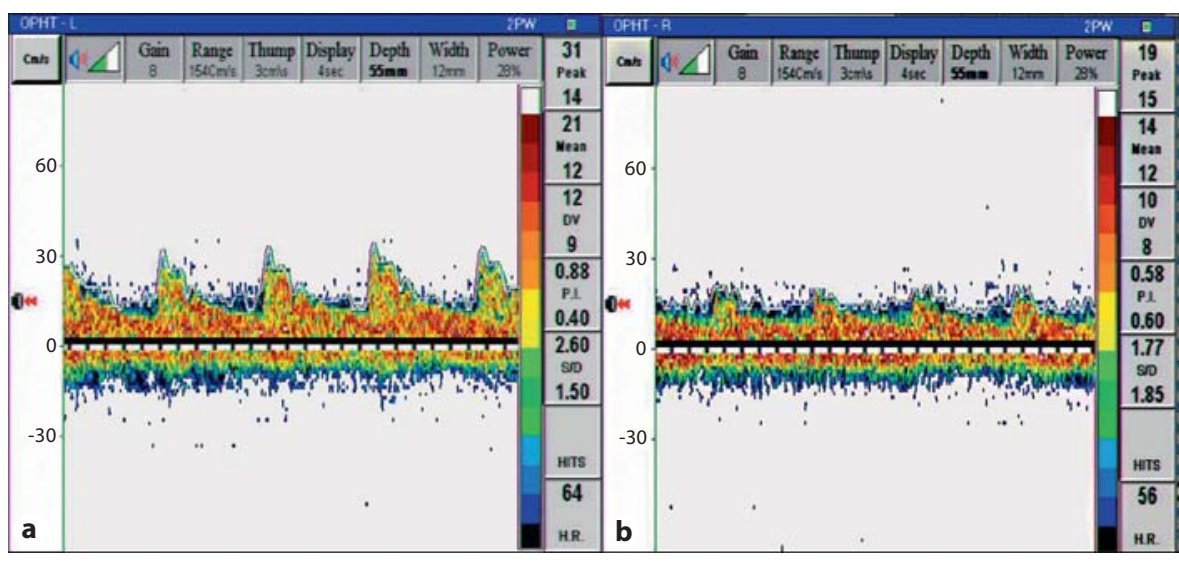

Fig. 1. Transcranial doppler. a The signals obtained from the left ophthalmic artery $(O A)$ were within normal limits. b The signals obtained from the right OA were blunted and showed decreased mean flow velocity (interside difference $=29 \%$ ).

his medical record did not show any atherosclerotic vascular disease.

Physical examination at admission did not reveal any bruits over either of the carotid arteries. No neurological deficits were detected. His blood pressure was $125 / 82 \mathrm{~mm} \mathrm{Hg}$, and his pulse rate was 72 beats/min and regular. Coagulation parameters, including antithrombin III, pro- teins $\mathrm{C}$ and $\mathrm{S}$, and fibrinogen, were within normal limits. Brain MRI and MR angiography, transthoracic echocardiography, and transesophageal echocardiography revealed no abnormal findings. The patient did not have a headache, and the values of ESR and CRP were within the normal range $(5 \mathrm{~mm} / \mathrm{h}$ and $0.5 \mathrm{mg} / \mathrm{dl}$, respectively). As autoimmune parameters, only

\section{KARGER}

Fax +41613061234

E-Mail karger@karger.ch

www.karger.com (c) 2008 S. Karger AG, Basel 0014-3022/08/0594-0202\$24.50/0

Accessible online at: www.karger.com/ene
Man Seok Park, MD

Department of Neurology

Chonnam National University Medical School, 8 Hak-Dong, Dong-Gu

Gwang Ju 501-757 (South Korea)

Tel. +82 62220 6415, Fax +82 62228 3461, E-Mail mspark@jnu.ac.kr 

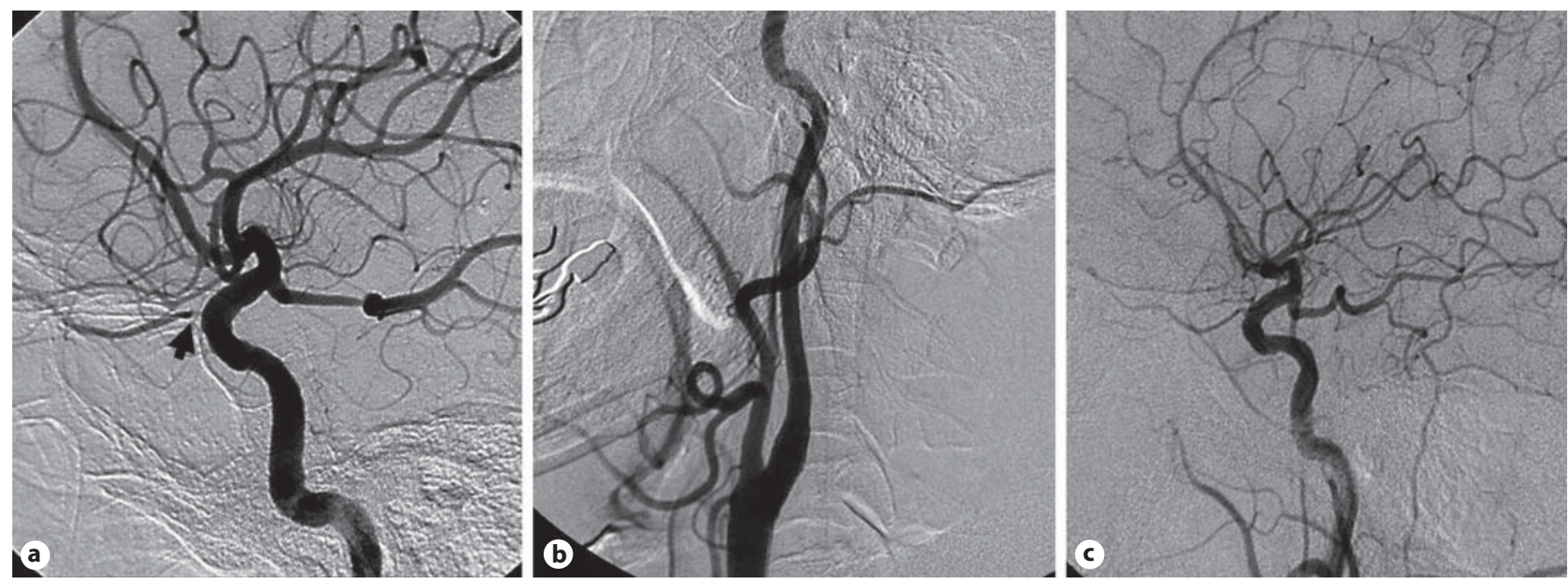

Fig. 2. Cerebral angiography. a Cerebral angiography showed stenosis of the right ophthalmic artery with poststenotic dilatation (arrow). b, c Cerebral angiography demonstrated no vascular stenosis on proximal portion of the right carotid artery and left ophthalmic artery.

ANA and ANCA were checked, and their results were within the normal range. Carotid duplex sonography did not demonstrate any stenosis or plaque in either of the carotid arteries. In transcranial Doppler, blunted wave form and decreased mean flow velocity were observed in the right ophthalmic artery (fig. 1). Severe stenosis with poststenotic dilatation of the right ophthalmic artery was shown in cerebral angiography, but both carotid arteries and the left ophthalmic artery were intact (fig. 2). Fundoscopic examination during TMB episodes showed arteriolar constriction in the right retina and a mildly pale perimacular region, but no cholesterol emboli were observed. Fluorescence angiography during TMB episodes showed delayed arterial and venous filling without any focal filling defect. Early morning occurrence of TMB in combination with orthostatic reaction suggests that TMB might be associated with hemodynamic compromise. After aspirin medication, no TMB attacks developed.

\section{Discussion}

TMB is predominantly attributed to microembolism of the ipsilateral internal carotid artery from atherosclerotic lesions or lesions of other structures, including the aortic arch and heart $[3,4]$. It can alert us to the presence of carotid artery disease, the surgical and medical treatment of which may have important bearing on patient management $[5,6]$.

Stenosis of the ophthalmic artery is very rare. According to a previous study, the prevalence of ophthalmic artery stenosis is approximately $2 \%$ of patients suffering from TMB [7]. There are two prevailing theories about TMB and ophthalmic artery stenosis. Braat et al. [1] reported a patient with isolated ophthalmic artery stenosis and one episode of TMB. During the episode, fundoscopy revealed a cholesterol embolus in the lower temporal branch of the central retinal artery. In this case, microembolism from the ophthalmic artery seemed to cause TMB, and anticoagulation was maintained successfully for preventing attacks. However, Nakajima et al. [3] postulated that high frequency of TMB attacks in the ophthalmic artery stenosis could be explained by platelet hyperaggregability and hemodynamic effect. They effectively treated a patient with aspirin for preventing attacks. In this case, TMB attacks were also resolved after aspirin medication. The hemodynamic effect and the reduction of stenosis with aspirin may have diminished the adherence of platelets in the stenotic area.

In our case, several episodes of orthostatic visual loss were reported, and cere- bral angiography revealed proximal stenosis of the right ophthalmic artery. Fluorescence angiography during visual loss revealed hypoperfusion of the right ophthalmic artery. Usually, the lack of blocked retinal vessels together with a long period of TMB can suggest a non-microembolic origin. Cholesterol emboli in a retinal artery branch are often found by fundoscopy in patients with TMB, which usually causes a benign atherothrombotic embolism [1, 8]. Unfortunately, no cholesterol embolism was observed at fundoscopy in our case. These results suggest that TMB in our patient was attributed to hemodynamic compromise rather than microembolism from the stenotic ophthalmic artery.

We report herein a patient with isolated ophthalmic artery stenosis and recurrent TMB. Decreased perfusion pressure of the ophthalmic artery was a possible cause of $\mathrm{TMB}$, and antiplatelet medication was effective in preventing recurrence. 


\section{References}

1 Braat AE, Hoogland PH, de Vries AC, de Mo van Otterloo JC: Amaurosis fugax and stenosis of the ophthalmic artery. Vasc Surg 2001; 35:141-143.

2 Gautier JC: Amaurosis fugax. N Engl J Med 1993;329:426-428.

3 Nakajima M, Kimura K, Minematsu K, Saito K, Takada T, Tanaka M: A case of frequently recurring amaurosis fugax with atherothrombotic ophthalmic artery occlusion. Neurology 2004;62:117-118.
4 Fisher CM: Transient monocular blindness associated with hemiplegia. Am Arch Ophthalmol 1952;106:497-501.

5 Ong TJ, Paine M, O’Day J: Retinal manifestations of ophthalmic artery hypoperfusion. Clin Exp Ophthalmol 2002;30:284291.

6 North American Symptomatic Carotid Endarterectomy Trial: Methods, patient characteristics, and progress. Stroke 1991;22:711720.
7 Adams HP, Putman SF, Corbett JJ: Amaurosis fugax: the results of arteriography in 59 patients. Stroke 1983;14:742-744.

8 Weinberger J, Bender AN, Yang WC: Amaurosis fugax associated with ophthalmic artery stenosis: clinical simulation of carotid artery disease. Stroke 1981;11:290-293. 